\title{
建筑工程基础施工技术管理措施探析
}

\author{
钟萍
}

浙江凯地基础工程有限公司

DOI:10.32629/btr.v2i1.1747

[摘 要] 随着物质文化生活水平的提高, 对工程项目建设质量也提出了更高的标准要求。基于施工技术与整体工程建设质量息 息相关,为此,切实加强技术管理可有效增强工程的安全稳定性。针对此,本文围绕建筑工程的基础施工技术管理展开深度探究。 [关键词]施工技术; 技术管理; 安全稳定性

建筑基础工程建设涉及诸多项目, 且技术类型也具有多 样性特征, 为此, 要加大对基础工程施工的重视度, 尽量避免 外界环境的干扰, 稳定工序运转, 促进建筑行业的快速发展。 在工程施工建设过程中, 大多数质量安全危险源来自于施工 现场, 换言之, 任何一个施工环节出现失误都会给工程质量 埋下隐患。由此可见, 采用正确的施工工艺是提高建筑工程 安全稳定性的关键。

\section{1 简述建筑工程地基基础施工技术}

\section{1 结合实际需求选择地基基础结构}

由于地基基础需要承担整体建筑架构的负荷力, 因此, 优 选建筑基础结构类型至关重要。在建筑地基基础结构选型时, 需参考施工现场的具体情况, 深入施工现场进行全面的地质 结构条件勘察, 以此为基准, 确定建筑基础构造类型。通常来 说, 地基基础构造形式多以独立基础和筏形基础为主, 其中, 独立基础的施工成本有限, 适用于地质结构条件较好的区域, 仅需保证承载力符合参数达到标准要求即可。而对地质结构 条件特殊的区域, 及主体结构高度有特殊要求的工程, 需要 通过扩张接触面面积的方式降低荷载力。

基于筏形基础的工序较为复杂, 其施工成本较高, 但筏 形基础的承载负荷强度良好, 可最大限度的保证整体建筑的 安全稳定性。因此, 在实际施工环节, 要结合工程所在区域地 质结构条件及建筑荷载力标准选定地基结构类型, 从根本上 保障建筑安全稳定性。

\section{2 地基基础施工流程}

\subsection{1 严格把控地基工程标高}

施工技术人员要严格控制地基工程的标高, 尽可能的减 小误差, 并将误差控制在合理范围内。在开展砌筑作业前, 需 全面检查基层标高, 并对局部低洼部分进行垫平处理。在勘 测地基基础结构时, 需复测标高, 并借助水平尺等专业器具 完成校对。在砌筑大脚时, 采用双面挂线的方式维持衡量水 平尺度。在填砖砌筑过程中, 为有效控制标高误差, 建议采用 小面积铺灰方式。

\section{2 .2 加大对定轴线的重视}

在建筑地基基础结构施工过程中, 要结合实际需求选择 恰当的施工技术, 全方位动态监控槽边推土作业, 避免机械 碰撞或土体移位等问题。在接通线时, 不仅要对准预先设置
中心桩, 还要使用排尺等实行合理控制。在完成基础部位的 砖筑后, 重新核对定轴线, 确保地基基础施工符合标准要求。

\section{2 .3 严格遵守标准规范落实防潮施工}

在工程施工建设过程中, 应着重把控防潮层的独立施工, 并将防潮层作为隐蔽性工程。同时在完成地基基础回填作业 后, 应采用砖筑的方式作为建筑防潮层施工技术, 以此避免土 体回填对防潮层造成损坏。需要格外注意的是, 普通工程规划 设计图纸中没有明确的防潮层设计标注, 因此, 必须严格把控 水泥砂浆的调配比例, 确保混凝土品质满足防潮施工要求。

\section{3 桩基施工技术的具体内容}

1.3. 1 灌注桩施工流程

通常, 灌注桩施工技术主要包括沉管灌注桩和钻孔灌注 桩两种。其中, 沉管灌注桩施工工序简便, 在外力的协助作用 下即可增强桩体打位的精确性。但需要注意的是, 一旦外力 作用出现偏差, 将会导致桩基基体损坏, 因此, 加强对桩基锤 击力度的控制也不容小觑。当下, 应用频率较高的桩基锤击 技术包括复打法、反插法等。

若使用复打法, 需对局部进行反复打击, 并采取连续性 单次击打的方式处理同一桩孔位置。使用单打法, 需要严格 控制桩体拔出的长度及震动速率, 通常, 桩体拔出长度控制 在 0. 5-1.0 米左右, 而相应的震动频率在 5-10 秒, 经过周而复 始的操作后, 将管道拔出。而反插法就是按照每拔出 0.5 米 就下插 0.3 米的频率反复运作, 直至管道顺利拔出。

在钻孔灌注桩施工过程中, 需采用专业机械设备完成钻 孔, 而后完成桩基浇筑作业与维护保养。当下, 钻孔灌注桩施 工的应用范围较为广泛, 在应用过程中, 需严格把控桩位中 心与护套中心的距离偏差, 积极做好回填处理, 避免在桩基 浇筑环节出现漏浆问题。另外, 采用分层注浆法开展注浆作 业, 并将浆层厚度控制在 50-60 厘米内。其具体施工流程为: 参考工程规划设计平面图, 确定桩基位置, 然后埋设防护套, 避免桩孔塌陷或地下水侵袭。一般来说, 桩孔保护筒多由厚度 在 4-8 毫米的钢板制成。保护筒内径要比机械钻头直径大 100-200 毫米, 并确保顶端超过地表水平面约 0.4-0.6 米。在 保证钻孔质量符合标准要求后, 需及时清理桩孔内存积的垃 圾杂物, 让孔低 500 毫米内的泥浆密度小于 1.25 克/立方米。 在浇筑混凝土时, 要使保护层厚度至少达到 35 毫米。 
1.3.2 应用预制桩施工技术的基本流程及要点

采用预制桩技术的首要前提是, 依据工程的基本概况制 作符合施工要求的桩基结构。在具体施工过程中, 可直接将 预先制作的桩体打入地层。当下, 应用频率较高的两种桩体 施工技术包括钢管预制桩和混凝土预制桩。通常, 钢管预制 桩施工技术多应用于特殊工程, 其主要采用 $\mathrm{H}$ 型钢桩。而混 凝土预制桩施工技术的核心是采用耐久性良好的混凝土桩 体。在打桩作业时, 需严格遵守规范, 将预制桩索具捆绑在桩 上端吊环附近 30 厘米范围内, 以此确保桩尖对准桩位中心。 待桩体缓慢插入土体中后, 需按照 1-2 次的锤击频率进行小 落距击打, 并将桩身垂直度控制在 $0.5 \%$ 以内。而后, 使用落 距小于 1.0 米的落锤击打桩体, 进而形成稳固的桩基础构造。 当下, 沉桩工艺主要包括振动沉桩和静力沉桩两种。在沉桩 过程中, 为避免土层结构遭受破坏, 要制定合理的沉桩方案, 调整桩基数据与间隔距离。

\section{2 强化建筑基础工程质量管理的具体策略}

2.1 制定完善的技术管理方案

高质量的工程建设需要以完善的施工规划方案为基础, 因此, 施工企业要制定科学合理的技术管理方案, 为强化工 程建设质量创造有利条件, 同时, 也为企业的可持续发展奠 定基础。在制定管理计划环节, 企业要针对每一个步骤制定 完善的计划, 进而确保施工建设有参考依据。此外, 应加大对 复杂型技术及特殊技术的重视度, 给予施工技术相应的监督 与指导。且完善的施工管理方案是实现整体工程建设质量目 标的先决条件。因此, 企业要进一步明确工程建设标准及技 术法规, 针对施工管理团队进行技能培训与职业素质教育, 从而强化安全责任意识与执行能力。

2.2 系统审核工程规划设计图纸

建筑施工技术管理过程中, 首要前提是明确整个项目设 计的目的及关键步骤。在工程建设前期阶段, 需积极落实施 工准备工作, 与工程设计单位保持联系, 针对工程施工图纸 进行统一会审。且在会审过程中, 需提出设计图纸的缺陷及 修整意见, 以此为切入点, 提高工程建设质量。

\section{3 明确责任制度}

建筑施工企业在开展技术管理环节, 要明确划分责任权 限, 将各施工步骤的责任落实到个人或团队, 避免出现质量
缺陷互相推诿。同时建立完善的责任制度, 逐级落实, 加深基 层管理人员的责任意识。再者, 要将整体技术管理目标划分 给各部门管理人员, 确保其充分落实管理工作, 强化实际管 理效果。

2.4 积极落实技术交底工作

技术交底在工程施工技术管理过程中发挥着不可替代 的作用, 能够从根本上保障工程建设质量。为此, 要针对每一 阶段性工程积极落实技术交底工作。施工企业在施工过程中, 应当加大对产品的保护力度, 重视质量安全问题, 强化管理。 由于技术交底是施工建设单位技术负责人向下一层技术单 位传递报告的过程，故而二者必须保持高效的信息交流，明 确工程进度, 确保工程建设工序的高效衔接。

2.5 强化工程建设质量

在施工建设过程中, 应当以工程承包合同或工程预先计 划作为实现整体工程质量目标的参考依据。其中, 主体施工 材料、施工技术及维护保养都属于质量控制的关键组成内容, 因此, 在施工建设过程中, 必须妥善处理各工序存在的缺陷, 确保工序的衔接。

\section{6 加强对进度管理的重视}

建筑施工技术管理应当充分参考预先预制的技术目标 及工程建设方案, 同时, 施工企业还要积极落实检查工作。换 言之, 施工企业要随时深入现场检查材料储备及供应情况, 了解施工能力, 切实解决施工过程遇到的各类突出性问题, 进而确保工程项目的高效运转, 提高整体工程建设质量。

\section{3 结束语}

综上所述, 建筑基础工程是整个建筑项目的核心, 提高 基础工程建设质量, 有助于增强整体工程安全稳定性。且施 工建设单位需结合实际需求, 加大对基础施工技术的管理力 度, 从根本上提升整体工程的质量等级。

\section{[参考文献]}

[1]刘泉泉.建筑工程施工技术管理水平有效提升策略 探究[J].门窗,2018(02):31.

[2]刘自兵.浅谈如何有效提升建筑工程施工技术管理水 平[J].智能城市,2018(08):45.

[3]张雪鹏.有效提升建筑工程施工技术管理水平研讨 [J]. 黑龙江科学,2018(16):63. 